\title{
LA DAMA DUENDE, LA ADAPTACIÓN DE ALFREDO CASTELLÓN (1979)
}

\author{
Raquel MARTÍNEZ BALLESTRÍN
}

A continuación realizaremos un breve comentario de la adaptación cinematográfica de la obra de Calderón La dama duende, que llevó a cabo Alfredo Castellón junto con RTVE en 1979. En este comentario nos centraremos en el tratamiento que realiza del espacio, y que cobra especial importancia en esta obra en tanto que la disposición escénica lleva consigo el peso del enredo argumental. Así mismo, también comentaremos el tratamiento que se lleva a cabo de otros aspectos que han llamado la atención de los críticos al aproximarse a la comedia calderoniana, como es el caso de la honra o la superstición.

De esta suerte, es importante destacar en primer lugar la fidelidad que presenta la adaptación cinematográfica. Así, tanto a nivel textual como a nivel estructural encontramos la perfecta sucesión de las escenas que desarrolla Calderón en su obra, además de una impecable caracterización dramática de todos los personajes: encontramos a una Beatriz desdeñosa, una Ángela ingeniosa, un Cosme humorístico, un don Manuel caballeroso, un don Luis sufriente y un don Juan enamorado. Es por esta razón por la que pondremos el acento en el tratamiento que se hará en la adaptación del paso del cuarto de Ángela al de don Manuel por la alacena, puesto que, tal y como veremos, constituye una incógnita aún desde el estudio y análisis del propio texto.

Así pues, y centrándonos en esta particularidad de la obra, y siempre en vista a su relación con el tratamiento que se le da en la película, encontramos el estudio realizado por Marc Vitse titulado "Sobre los espacios en La dama duende: el cuarto de don Manuel". En este artículo pretende el hispanista realizar el mapa de las dos ubicaciones que constituyen el origen del enredo a partir del análisis del texto, llegando a la conclusión de la existencia de una distancia considerable entre los dos aposentos: Hay, en primer lugar, la aseveración de Isabel, que precisa (vv. 585-88) que la puerta modificada por don Juan en el cuarto de Manuel no da al cuarto de Ángela, sino a un «jardín». Este jardín interior de la casa -que no se volverá a mencionar- se sitúa pues en algún trozo del camino que conduce del cuarto de Angela, en que probablemente se desarrolla la escena que estudiamos (1996:342).

La distancia que defiende Marc Vitse llega a cuantificarla atendiendo al número de versos recogidos en el parlamento de los personajes que la cruzan, computando una media de cuarenta versos, lo que le permite suponer una distancia considerable. En el caso de la adaptación que comentamos, encontramos un fiel respeto de la mayoría de las características apuntadas por el investigador. De esta forma, en primer lugar encontramos la distribución del aposento de don Manuel, que encaja con la descripción que realiza Vitse: "este bloque 


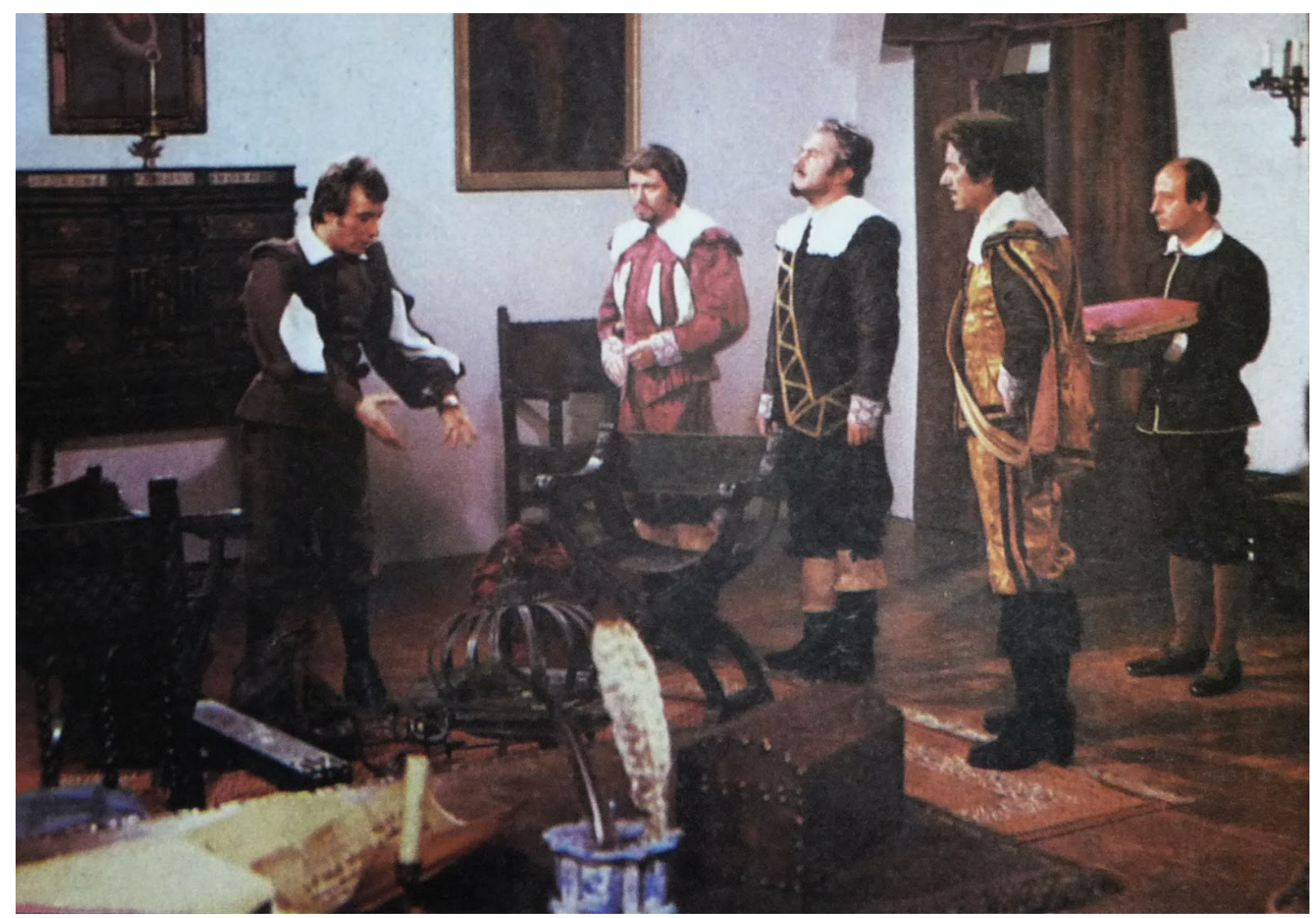

La Dama Duende. Alfredo Castellón

espacial -cuarto se ha de entender en su significación áurea de «parte de la casa destinada a alguna persona con su familia» (Auf), o sea algo comparable con los appartements de las piezas de Corneille" (1996:339). Con la salida de este al exterior, constituyendo la alacena la comunicación con el interior de la casa que ha sido tapida.

$Y$, en segundo lugar, encontramos la no contigüidad entre los aposentos que antes señalábamos, de tal forma que en la adaptación existe un corredor desde la alacena del cuarto de don Manuel al de Ángela, que es aprovechado por los personajes para pronunciar los versos previstos por Calderón, según la distancia que existe entre los aposentos. No obstante, no hay rastro en la adaptación del jardín al que apuntaba Marc Vitse, aunque la razón es, sin duda, la ausencia de referencias a este a lo largo del texto calderoniano.

De hecho y al rescate de esta misma cuestión de la espacialidad encontramos las reflexiones orientadas a la honra y a lo lúdico que lleva a cabo lgnacio Arellano en su artículo "La dama duende y sus notables casos". Por lo que respecta al tratamiento de la honra, encontramos una presencia de esta depurada y lejana a las consideraciones que Arellano recoge como testigo de otros investigadores que llevan a cabo interpretaciones incestuosas o freudianas, por las que se sexualizan los espacios y se entiende el paso por la alacena como una suerte de profanación.

Situándonos de parte de Ignacio Arellano, consideramos lejanas estas interpretaciones, que sobrepasan al texto $y$, consecuentemente, a la adaptación que comentamos, libre de cualquier consideración que vaya más allá de un intento de conservación de la honra caballeresca, con los duelos y el matrimonio como únicos protagonistas. Representante de 


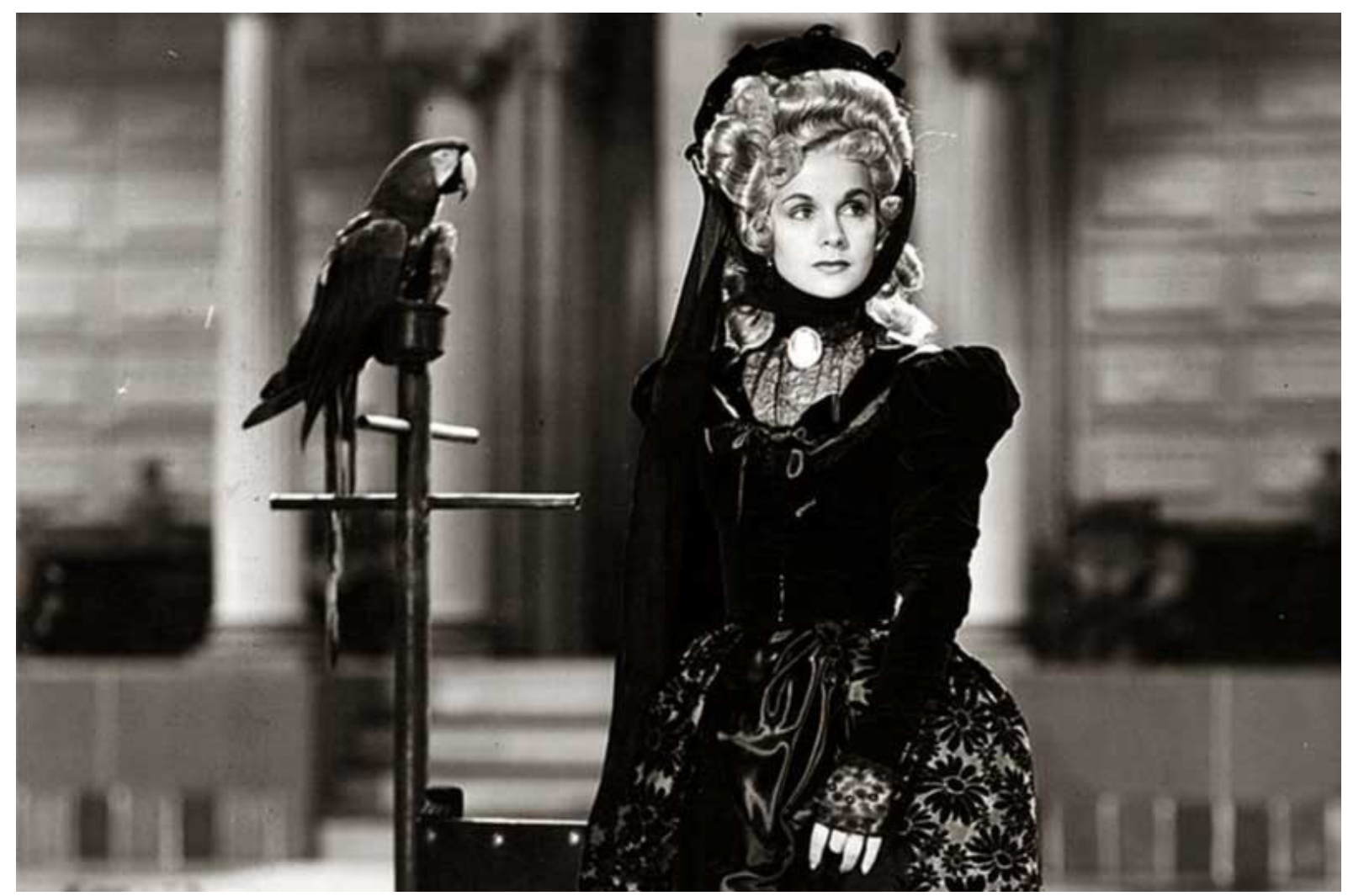

La Dama Duende. Luis Salavsky

esta honra será don Manuel y así lo encontramos en la adaptación, tanto cuando decide interceder por la desconocida encubierta como cuando defiende a doña Ángela de la ira de sus hermanos.

Así mismo, manteniendo la fidelidad que presenta la adaptación, encontramos el elemento lúdico delimitado a los elementos sobre los que Calderón introdujo la carga cómica: los equívocos y el personaje del "bufón" encarnado por Cosme. En esta línea señala Ignacio Arellano que "Los enredos proceden de la tramoya montada por doña Ángela, de los malos entendimientos de palabras y hechos, y de la misma calidad azarosa de la vida" (2001:131). En este sentido, Cosme se mantiene en la adaptación, tal y como ocurre en la obra, como el depositario de un humor que se caracteriza por los juegos de palabras y un considerable ingenio, y así lo caracteriza Valbuena-Briones cuando señala sobre él: "Parlamento gracioso, pero erudito" (1975:21).

No obstante, no encontramos un humor limitado a la figura de Cosme, sino que lo encontramos también en el juego caballeresco que se establece entre los protagonistas. Tal y como señala Valbuena-Briones: "El capitán acepta de buen grado el papel quijotesco que le adjudica su admiradora y le escribe en un estilo propio de los libros de caballerías y firma su carta con el nombre de "El caballero de la dama duende»" (1975:18-19). Esta relación misteriosa será, precisamente, lo que derive a la dualidad que no pocos investigadores han señalado en torno al cristianismo y la superstición.

Debemos destacar de la adaptación la mesura con la que se trata esta aparente contradicción. Así, Cosme caracterizaría la figura del supersticioso mientras que don Manuel 
haría gala de su racionalismo cuando se enfrentan a los misterios de la "dama duende". No obstante, Ignacio Arellano recogerá la consideración que Marc Vitse realiza en el prólogo de la obra, matizando lo que algunos consideraban como "superstición" por falta de valor. Exactamente son estas las sensaciones que transmiten tanto don Manuel como Cosme en la adaptación. Destaca en esta, así pues, la templanza de don Manuel, que casi se burla de las dudas de su criado, con los miedos de Cosme, quien entra templando, murmurando y convocando la tranquilidad de ese supuesto duende que tanto le atemoriza.

Se trata, en definitiva, de una adaptación fiel que, contando con los avances cinematográficos, suple algunos rasgos de una puesta en escena teatral, si bien no mantiene la vivacidad y la fugacidad del hecho dramático, imposible de capturar por la cámara. Así, encontramos un magnífico tratamiento del espacio, que demuestra un gran trabajo de análisis y comprensión textual antes de la puesta en escena. Y, a este mismo estudio del texto debemos la imagen del honor y la honra, que no deja dudas ni da pie a tergiversaciones, así como la clara muestra de esta "falta de valor" de Cosme frente a complicadas teorías de superstición y racionalidad. En definitiva, la adaptación transmite la base que persigue la obra siendo coherente con ese género de capa y espada: "es el marco convencional en el que los elementos de la pieza cobran su sentido dramatúrgico. Muchas de las lecturas desviadas lo son precisamente por ignorar esta inserción en el género" (Arellano, 2001:127).

\section{BIBLIOGRAFÍA CONSULTADA}

ARELLANO, Ignacio (2001). "La dama duende y sus notables casos", Cuadernos de teatro clásico, n¹5, pp. 127-141.

URL: https://dadun.unav.edu/handle/10171/19925 [Visitada el 12/05/20].

VALBUENA-BRIONES, Ángel (1975). "La técnica dramática y el efecto cómico en "La dama duende", de Calderón", Arbor, vol. 90, n³49, pp. 15-26.

URL: https://revistas.uam.es/edadoro/article/download/9308/9541 [Visitada el12/05/20].

VITSE, Marc (1996). "Sobre los espacios en La dama duende: el cuarto de don Manuel", RILCE, vol. 12, n², pp. 337-356.

URL: https://dadun.unav.edu/bitstream/10171/4320/1/ART\%c3\%8dCULO\%206.\%20 SOBRE\%20LOS\%20ESPACIOS\%20N\%20LA\%20DAMA\%20DUENDE\%2C\%20EL\%20 CUARTO\%20DE\%20DO [Visitada el 12/05/20]. 